\title{
Evaluation of transvaginal ultrasound role in the prediction of adenomyosis: correlation with histopathology
}

\author{
Naglaa Ali M. Hussein ${ }^{1 *}$, Mohammed H. El Refaey ${ }^{2}$
}

${ }^{1}$ Department of Obstetrics and Gynecology, Tanta University, Tanta, Egypt
${ }^{2}$ Department of Diagnostic Radiology, Tanta University, Tanta, Egypt

Received: 17 June 2021

Accepted: 13 July 2021

Revised: 15 July 2021

\section{*Correspondence:}

Naglaa Ali M. Hussein,

E-mail: ahmedfarragg346@gmail.com

Copyright: (c) the author(s), publisher and licensee Medip Academy. This is an open-access article distributed under the terms of the Creative Commons Attribution Non-Commercial License, which permits unrestricted non-commercial use, distribution, and reproduction in any medium, provided the original work is properly cited.

\section{ABSTRACT}

Background: Adenomyosis is a common gynecologic disorder that primarily affects women of reproductive age that has reported incidence of $5-70 \%$ in surgical and postmortem specimens. The aim of this study was to evaluate the accuracy of various transvaginal sonographic findings in adenomyosis by comparing them with histopathological results and to determine the most valuable sonographic feature in the diagnosis of adenomyosis.

Methods: All transvaginal US findings were correlated with those from histologic examination. The frequency of presenting symptoms and signs of adenomyosis were evaluated. Transvaginal US depicted 10 of 12 pathologically proved cases of adenomyosis. Adenomyosis was correctly ruled out in 33 of 38 patients.

Results: Transvaginal US had a sensitivity of $83 \%$, a specificity of $86 \%$, and a positive and negative predictive value of $66 \%$ and $94 \%$, respectively. Of the 10 patients with true-positive findings at transvaginal US, the myometrium demonstrated heterogeneous with or without the presence of cysts in nine (75\%) patients, linear striation in four (33.3\%) patients and globular uterus in six $(50 \%)$ patients. Three $(25 \%)$ of 12 cases of adenomyosis had an enlarged uterus, adenomyosis was a significant association with high parity.

Conclusions: Adenomyosis can be diagnosed with a considerable accuracy by transvaginal ultrasound. The most common sonographic criteria of adenomyosis are heterogeneous myometrial appearance while the most specific criteria are myometrial cysts, sub-endometrial echogenic linear striations and globular configuration of the uterus.

Keywords: Transvaginal ultrasound, Adenomyosis, Histopathology

\section{INTRODUCTION}

Adenomyosis is a common gynecologic condition that affects menstruating women. It is characterized by ingrowths of the endometrial cells into the myometrium. Diagnosis based on clinical findings is usually difficult because of the nonspecific nature of the symptoms and the frequent coexistence of other pelvic diseases. Until recently, the diagnosis was established at biopsy or surgery. ${ }^{1}$ With the advent of high-resolution imaging techniques, correct diagnosis can be established with imaging modalities. ${ }^{2}$ The three most common methods for diagnosis of adenomyosis are magnetic resonance imaging, transabdominal ultrasonography and transvaginal ultrasonography (TVS). ${ }^{3}$

TVS, which can improve spatial resolution with its higher frequency, is known to be accurate in diagnosing adenomyosis, TVS is a more feasible option. Moreover, TVS is also much more cost effective than MRI and is generally more readily available in the office to most practicing gynecologists is, but it actually has limitations in tissue characterization. Magnetic resonance imaging (MRI) is also an accurate, noninvasive modality for diagnosing adenomyosis. Precise knowledge of histopathologic backgrounds of the disease helps in 
understanding the nature of adenomyosis and its clinical and sonographic picture. ${ }^{4}$ Diagnostic criteria of adenomyosis by TVS were as follows: globular and/or asymmetric uterus was defined as a regular enlarged uterus with possible myometrial asymmetry unrelated to leiomyoma.

Heterogeneous myometrium was defined by the presence of an indistinctly defined myometrial area with decreased or increased echogenicity. Myometrial hypoechoic linear striations were defined as radiate pattern of thin acoustic shadowing not arising from echogenic foci and/or leiomyoma. ${ }^{5}$ Myometrial cyst was defined as a round anechoic area of 1-7 $\mathrm{mm}$ diameter. The diagnosis was made when at least one of the above criteria was met. ${ }^{6}$

\section{Aim}

The aim of the study was to evaluate the accuracy of various transvaginal sonographic findings in diagnosis of adenomyosis by comparing them with histopathological results and to determine the most valuable sonographic feature in the diagnosis of adenomyosis.

\section{METHODS}

This was a cross-sectional diagnostic study carried out at department of gynecology and obstetrics, Tanta university hospitals in the period from May 2020 to April 2021. Approvals obtained for performing the study from ethical committee in faculty and from patient or people included in the study (written consent taken from participants). This study performed on fifty perimenopausal women.

Inclusion criteria included perimenopausal women (age >40 years and menopause not established yet), women complaining of menorrhagia and/or dysmenorrhea, women not responding to treatment and women planned for hysterectomy.

Exclusion criteria included women seeking further pregnancy, women undergoing conservative surgical procedures such as laparoscopic myometrial electrocoagulation, laparoscopic adenomyomectomy and hysteroscopic endometrial resection or ablation and patient unfit for surgery.

In this study, all cases subjected to the following- (a) full history taking; (b) physical examination; and (c) routine laboratory investigations.

\section{Transvaginal US}

All women underwent 2D transvaginal ultrasound examination by the same sonographer.

\section{Apparatus used}

Volusion 730 promachine CGE health care, Austiria with endovaginal probe 4-7 mhz.

\section{During examination}

Uterine size, endometrial thickness, endometrialmyometrial junction and sub-endometrial halo thickness measured.

\section{Diagnosis of adenomyosis}

\section{Common ultrasonic features}

(a) uterine enlargement- globular uterine enlargement that is generally up to $12 \mathrm{~cm}$ in uterine length and that is not explained by the presence of leiomyomata is a characteristic finding. (b) Cystic anechoic spaces or lakes in the myometrium- The cystic anechoic spaces within the myometrium are variable in size and can occur throughout the myometrium. The cystic changes in the outer myometrium may on occasion represent small arcuate veins rather than adenomyomas. The application of color Doppler imaging at low velocity scales may help in this differentiation. (c) Sub-endometrial echogenic linear striations- Invasion of the endometrial glands into the subendometrial tissue induces a hyperplastic reaction, which appears as echogenic linear striations. (d) Heterogeneous echo texture- there is a lack of homogeneity within the myometrium with evidence of architectural disturbance. This finding has been shown to be the most predictive of adenomyosis. (e) obscure endometrial/myometrial borderInvasion of the myometrium by the glands also obscures the normally distinct endometrial/myometrial border). (f) Thickening of the transition zone- This zone is a layer that appears as a hypoechoic halo surrounding the endometrial layer. A thickness of $12 \mathrm{~mm}$ or greater has been shown to be associated with adenomyosis.

\section{Histopathologic features}

All patients underwent hysterectomy within a median of (seven) days after undergoing endovaginal US. All histopathological examinations were performed by the same pathologist, who was blinded to the sonographic findings.

Macroscopically, adenomyosis was diagnosed by an enlarged uterus, a globular and/or asymmetrical uterus, and a dense irregularly fasciculated myometrium with small cavities $(0.5-10 \mathrm{~mm})$.

Histologically, the presence of ectopic endometrial glands and/or stroma associated with surrounding smooth-muscle hypertrophy and hyperplasia located $2.5 \mathrm{~mm}$ beyond the endometrial-myometrial junction was considered diagnostic of adenomyosis by Ueki et al.

\section{Statistical analysis}

All data were collected, tabulated, and statistically analyzed using SPSS 18.0 for windows (SPSS Inc., Chicago, IL, USA) and MedCalc 13. 


\section{RESULTS}

This study included fifty perimenopausal women complaining of menorrhagia and/or dysmenorrhea planned for hysterectomy.

Adenomyosis was diagnosed at histologic examination in $12(24 \%)$. With findings at histologic examination as a standard of reference, TV U/S correctly depicted the presence of adenomyosis in 10 patients and the absence of adenomyosis in 33 patients. There were 5 false-positive and 2 false negative diagnoses. Table 1 shows demographic data and obstetric history of cases none of which is statistically significant except for BMI and parity. As shown in Table 2 clinical findings of adenomyosis are nonspecific and only bulky uterus by BME (less than 12 weeks) is statistically significant. -BME: bimanual examination the associated pathologic findings of

Table 1: Comparison between cases with adenomyosis and cases without adenomyosis as regard demographic data and obstetric history.

\begin{tabular}{|c|c|c|c|c|c|}
\hline $\begin{array}{l}\text { Demographic data and } \\
\text { obstetric history }\end{array}$ & Total & $\begin{array}{l}\text { Adenomyosis } \\
(\mathrm{N}=12)\end{array}$ & $\begin{array}{l}\text { No adenomyosis } \\
(\mathrm{N}=38)\end{array}$ & Test & P value (Sig.) \\
\hline Age (years) & & & & $\mathrm{t}$ & \\
\hline Mean \pm SD & $44.20 \pm 2.99$ & $44.08 \pm 2.27$ & $44.24 \pm 3.20$ & -0.034 & $0.973(\mathrm{NS})$ \\
\hline Parity & & & & t & \\
\hline Mean \pm SD & $4.26 \pm 1.50$ & $5.42 \pm 2.10$ & $3.89 \pm 1.06$ & -1.944 & 0.048 (NS) \\
\hline Previous uterine scar & & & & $\chi^{2}$ & $0.185(\mathrm{NS})$ \\
\hline No (N\%) & $40(80 \%)$ & $66.7 \%$ & $84.2 \%$ & 1.754 & \\
\hline Yes (N\%) & $10(10 \%)$ & $33.3 \%$ & $15.6 \%$ & & \\
\hline BMI & & & & $\mathrm{t}$ & \\
\hline Mean \pm SD & $44.20 \pm 3.34$ & $26.900 \pm 2.412$ & $18.0588 \pm 3.470$ & 2.215 & $<0.05(\mathrm{~S})$ \\
\hline
\end{tabular}

Note: MW- Mann Whitney U test; $p<0.05$ is significant; t- independent Student t-test; $\chi 2$ - Chi square test; BMI- Body mass index; Sig.significance.

Table 2: Comparison between cases with adenomyosis and cases without adenomyosis as regard clinical findings.

\begin{tabular}{|c|c|c|c|c|c|c|c|c|}
\hline \multirow[t]{2}{*}{ Clinical findings } & \multicolumn{2}{|c|}{ Total } & \multicolumn{2}{|c|}{$\begin{array}{l}\text { Adenomyosis } \\
(\mathrm{N}=\mathbf{1 2})\end{array}$} & \multicolumn{2}{|c|}{$\begin{array}{l}\text { No adenomyosis } \\
(\mathrm{N}=\mathbf{3 8})\end{array}$} & \multirow[t]{2}{*}{$x^{2}$} & \multirow[t]{2}{*}{ P value (Sig.) } \\
\hline & $\mathbf{N}$ & $\%$ & $\mathbf{N}$ & $\%$ & $\mathbf{N}$ & $\%$ & & \\
\hline Menorrhagia & 25 & 50 & 8 & 66.7 & 17 & 44.7 & 1.754 & $0.185(\mathrm{NS})$ \\
\hline Menometrorrhagia & 17 & 34 & 3 & 25 & 14 & 36.8 & 0.570 & $0.450(\mathrm{NS})$ \\
\hline Dysmenorrhea & 20 & 40 & 4 & 33.3 & 13 & 15.8 & 1.754 & $0.185(\mathrm{NS})$ \\
\hline Menorrhagia and dysmenorrhea & 15 & 30 & 8 & 66.7 & 7 & 18.4 & 0.247 & 0.619 (NS) \\
\hline $\begin{array}{l}\text { Bulky uterus by BME (less than } \\
12 \text { weeks) }\end{array}$ & 23 & 46 & 10 & 83.3 & 13 & 34.2 & 7.37 & $0.005(\mathrm{~S})$ \\
\hline
\end{tabular}

Table 3: Comparison between cases with adenomyosis and cases without adenomyosis as regard other histopathological findings.

\begin{tabular}{|c|c|c|c|c|c|c|c|c|}
\hline \multirow{2}{*}{ Other histopathological findings } & \multicolumn{2}{|c|}{ Total } & \multicolumn{2}{|c|}{$\begin{array}{l}\text { Adenomyosis } \\
(\mathrm{N}=12)\end{array}$} & \multicolumn{2}{|c|}{$\begin{array}{l}\text { No adenomyosis } \\
(\mathrm{N}=\mathbf{3 8})\end{array}$} & \multirow[t]{2}{*}{$\chi^{2}$} & \multirow[t]{2}{*}{ P value (Sig.) } \\
\hline & $\mathbf{N}$ & $\%$ & $\mathbf{N}$ & $\%$ & $\mathbf{N}$ & $\%$ & & \\
\hline Fibroid & 31 & 62 & 6 & 50 & 25 & 65.8 & 0.965 & $0.326(\mathrm{NS})$ \\
\hline Endometrial hyperplasia/polyp & 15 & 30 & 3 & 25 & 12 & 31.6 & 0.188 & $0.665(\mathrm{NS})$ \\
\hline Endometrial carcinoma & 3 & 6 & 2 & 16.7 & 1 & 2.6 & 3.185 & $0.074(\mathrm{NS})$ \\
\hline Endometriosis & 5 & 10 & 3 & 25 & 2 & 5.26 & 1.954 & 0.098 (NS) \\
\hline
\end{tabular}


Table 4: Agreement between TV U/S provisional diagnosis and histopathological final diagnosis.

\begin{tabular}{|c|c|c|c|}
\hline \multirow{2}{*}{ TV U/S } & \multicolumn{2}{|l|}{ Histopathology } & \multirow{2}{*}{ Total } \\
\hline & Adenomyosis & No adenomyosis & \\
\hline Adenomyosis & 10 & 5 & 15 \\
\hline No adenomyosis & 2 & 33 & 35 \\
\hline Total & 12 & 38 & 50 \\
\hline
\end{tabular}

Note: McNemar test: $\mathrm{p}=0.453$ (NS); Inter-rater agreement: Kappa=0.646, $\mathrm{p}<0.001$ (HS); $<<0.05$ is significant.

Table 5: Comparison between cases with adenomyosis and cases without adenomyosis as regard TV U/S findings.

\begin{tabular}{|c|c|c|c|c|c|c|c|c|c|}
\hline \multirow[t]{2}{*}{ TV U/S findings } & \multicolumn{3}{|c|}{ Total } & \multicolumn{2}{|c|}{$\begin{array}{l}\text { Adenomyosis } \\
(\mathrm{N}=12)\end{array}$} & \multicolumn{2}{|c|}{$\begin{array}{l}\text { No adenomyosis } \\
(\mathbf{N}=\mathbf{3 8})\end{array}$} & \multirow[t]{2}{*}{$x^{2}$} & \multirow[t]{2}{*}{ P value (Sig.) } \\
\hline & $\mathbf{N}$ & $\%$ & & $\mathbf{N}$ & $\%$ & $\mathbf{N}$ & $\%$ & & \\
\hline \multirow{2}{*}{ Myometrial cyst } & \multirow{2}{*}{5} & \multirow{2}{*}{10} & No & 9 & 75 & 36 & 94.7 & \multirow{2}{*}{3.947} & \multirow{2}{*}{$0.047(\mathrm{~S})$} \\
\hline & & & Yes & 3 & 25 & 2 & 5.3 & & \\
\hline \multirow{2}{*}{$\begin{array}{l}\text { Heterogenous } \\
\text { myometrium }\end{array}$} & \multirow{2}{*}{13} & \multirow{2}{*}{26} & No & 3 & 25 & 34 & 89.5 & \multirow{2}{*}{19.704} & \multirow{2}{*}{$<0.001(\mathrm{HS})$} \\
\hline & & & Yes & 9 & 75 & 4 & 10.5 & & \\
\hline \multirow{2}{*}{$\begin{array}{l}\text { Asymmetric antero- } \\
\text { posterior uterine wall }\end{array}$} & \multirow{2}{*}{4} & \multirow{2}{*}{8} & No & 11 & 91.7 & 35 & 92.1 & \multirow{2}{*}{0.002} & \multirow{2}{*}{$0.961(\mathrm{NS})$} \\
\hline & & & Yes & 1 & 8.3 & 3 & 7.9 & & \\
\hline \multirow{2}{*}{$\begin{array}{l}\text { Sub-endometrial } \\
\text { echogenic linear striation }\end{array}$} & \multirow{2}{*}{4} & \multirow{2}{*}{8} & No & 8 & 66.7 & 38 & 100 & \multirow{2}{*}{13.768} & \multirow{2}{*}{$<0.001(\mathrm{HS})$} \\
\hline & & & Yes & 4 & 33.3 & 0 & 0 & & \\
\hline \multirow{2}{*}{ Globular configuration } & \multirow{2}{*}{7} & \multirow{2}{*}{14} & No & 6 & 50 & 37 & 97.4 & \multirow{2}{*}{16.996} & \multirow{2}{*}{$<0.001$ (HS) } \\
\hline & & & Yes & 6 & 50 & 1 & 2.6 & & \\
\hline \multirow{2}{*}{$\begin{array}{l}\text { Poor definition of } \\
\text { endomyometrial junction }\end{array}$} & \multirow{2}{*}{4} & \multirow{2}{*}{8} & No & 10 & 83.3 & 36 & 94.7 & \multirow{2}{*}{1.611} & \multirow{2}{*}{$0.204(\mathrm{NS})$} \\
\hline & & & Yes & 2 & 16.7 & 5 & 5.3 & & \\
\hline Focal lesion & 6 & 12 & No & 10 & 83.3 & 15 & 39.47 & 2047 & 0520 (NS) \\
\hline Focal lesion & 0 & 12 & Yes & 2 & 16.7 & 25 & 60.52 & 2.041 & $0.520(\mathrm{NSS})$ \\
\hline
\end{tabular}

Table 6: Diagnostic performance of TV U/S for the diagnosis of adenomyosis $(\mathrm{N}=50)$.

\begin{tabular}{|llllllll|}
\hline Variables & SN $(\%)$ & SP $(\%)$ & PPV (\%) & NPV (\%) & Accuracy $(\%)$ & LR+ LR- \\
\hline Overall & 83.3 & 86.8 & 66.7 & 94.3 & 85.4 & 6.3 & 0.2 \\
\hline Myometrial cyst & 25 & 94.7 & 60 & 80 & 86.00 & 4.8 & 0.8 \\
\hline Heterogenous myometrium & 75 & 89.5 & 69.2 & 91.9 & 83.5 & 7.1 & 0.3 \\
\hline $\begin{array}{l}\text { asymmetric antero-posterior } \\
\text { uterine wall }\end{array}$ & 8.3 & 92.1 & 25 & 76.1 & 57.8 & 1.1 & 1 \\
\hline $\begin{array}{l}\text { Sub-endometrial echogenic } \\
\text { linear striation }\end{array}$ & 33.3 & 100 & 100 & 82.6 & 86.00 & 12.7 & 0.7 \\
\hline Globular configuration & 50 & 97.4 & 85.7 & 86 & 77.9 & 19 & 0.5 \\
\hline $\begin{array}{l}\text { Poor definition of } \\
\text { endomyometrial junction }\end{array}$ & 16.7 & 94.9 & 50 & 78.7 & 62.8 & 3.3 & 0.9 \\
\hline
\end{tabular}

Note: SN: sensitivity; SP: specificity; PPV: positive predictive value; NPV: negative predictive value- LR+: positive likelihood ratio; LR: negative likelihood ratio.

\section{DISCUSSION}

Adenomyosis is one of the most common uterine diseases seen in the histopathological examination of hysterectomy specimens. The reported frequency varies widely, from 5 to $70 \% .^{1}$ This wide range may be a result of differences in histological criteria for the diagnosis of adenomyosis, the degree of care with which pathological specimens are examined, or the number of sampling sites considered in previous studies. ${ }^{8}$ In this study the mean for parity was 5.42 in the 12 cases diagnosed as adenomyosis while the mean for parity was 3.89 in the rest of cases without adenomyosis giving a statistically significant correlation between parity and adenomyosis $(\mathrm{p}<0.05)$. Similar findings had emerged in the few epidemiological studies on the issue. ${ }^{9}$ Foci of adenomyosis may be included in the myometrium due to the aggressive action of the trophoblast on the extension of myometrial fibers during pregnancy. Otherwise, the hormonal changes of pregnancy may favor the development of islands of adenomyosis.

Eight $(66.7 \%)$ out of 12 cases diagnosed as adenomyosis had menorrhagia yet there was no statistically significant correlation between menorrhagia and adenomyosis in this 
study, the result of this study agrees with the literature in which menorrhagia is the presenting symptom in $40-50 \%$ of patients with adenomyosis. 4 (33.3\%) out of 12 cases diagnosed as adenomyosis had dysmenorrhea which also agrees with the literature in which dysmenorrhea is the presenting symptom in $30-40 \%$ of patients of adenomyosis. $^{9}$

There is a significant statistical correlation between the uterine size and adenomyosis in this study. As 10 (83.3\%) of 12 cases diagnosed as adenomyosis had an enlarged uterine size by bimanual examination, this also correlates with the literature as in her study $(89.5 \%)$ of uteri were bulky, $6.7 \%$ were normal in size and $3.8 \%$ were atrophied. ${ }^{10}$

There was no statistically significant correlation between hypertension, diabetes mellitus, history of hormonal treatment, history of fractional curettage and adenomyosis as a constant variable.

It is recognized that adenomyosis is rarely a single histopathological diagnosis the data support the concept that adenomyosis is a hormone dependent disorder, as it is associated with persistently elevated estrogen level. ${ }^{11}$ Bazot et al found that adenomyotic uteri were accompanied by additional pelvic disorders in $82.5 \%$ of the cases in their study. ${ }^{12}$

There was a significant positive correlation between development of adenomyosis and presence of leiomyoma $(p<0.0001)$, history of previous abortion $(p<0.0001)$, history of previous pregnancy $(\mathrm{p}=0.0002)$, and normal body mass index $(\mathrm{p}<0.0001)$. However, no significant relationship existed between development of adenomyosis and smoking $(p>0.4300)$, normal delivery $(p=0.9600)$, cesarean delivery $(\mathrm{p}=0.5705)$, endometrial hyperplasia $(p=0.1721)$, or ovarian endometriosis $(p=0.8595) .{ }^{13}$

In this study adenomyosis was diagnosed with leiomyomas in $(50 \%)$ followed by endometrial polyp $(41.7 \%)$, endometrial hyperplasia $(25 \%)$ and endometrial carcinoma (16.7\%). There was no statistically significant correlation between adenomyosis and the associated pathology (endometrial hyperplasia, endometrial carcinoma and leiomyomas) although other mentioned that there is a relationship between endometrial hyperplasia and adenomyosis and mentioned that there is a relationship between endometrial carcinoma and adenomyosis. ${ }^{14,15} \mathrm{In}$ this study there was a significant positive correlation between development of adenomyosis and normal BMI.

Bromley et al studied 51 patients in whom a prospective diagnosis of adenomyosis was suspected on the basis of sonographic findings and who had undergone hysterectomy at a single hospital. Forty-three (43) of fiftyone (51) $(84.3 \%)$ patients sonographically suspected of having adenomyosis were confirmed as having adenomyosis by pathologic examination. All patients with adenomyosis had a mottled heterogeneous appearing uterus, 95\% had a globular uterus, $82 \%$ had small myometrial lucent areas, and $82 \%$ had an indistinct endometrial stripe. ${ }^{16}$

In these results $(67 \%)$ out of 15 patients sonographically suspected of having adenomyosis were confirmed as having adenomyosis by pathologic examination. $75 \%$ out of 12 cases diagnosed as adenomyosis had a mottled heterogeneous appearing uterus, $50 \%$ had a globular uterus, (25\%) had small myometrial lucent areas. (33.3\%) had sub-endometrial echogenic linear striations, (16.7\%) had poor definition of the endometrial-myometrial junction, and $(8.3 \%)$ had asymmetrical thickness of the antero-posterior wall of the myometrium.

The discrepancy between the results may be due to my small sample size as we studied only 15 patients sonographically suspected of having adenomyosis while Bromley et al studied 51 patients.

In this study transvaginal US had a sensitivity of $83.3 \%$ (95\%CI:62.2-100), specificity of $86.8 \%$ (95\%CI: $76.1-$ 97.6), positive predictive value of $66.7 \%$ (95\%CI: 42.8 90.5) and negative predictive value of $94.3 \%$ (95\% CI: 86.6-100) and an accuracy of $85.4 \%$ (95\%CI: 75.6-95.2) in the diagnosis of adenomyosis.

In comparison to study done by Fedele et al using transvaginal US, reported $87 \%$ sensitivity and a $99 \%$ specificity in the diagnosis of 23 localized adenomyosis in 405 patients undergoing surgery for symptomatic uterine masses. In addition, the same group of investigators evaluated the accuracy of endovaginal US in the diagnosis of diffuse adenomyosis in 43 patients undergoing surgery for menorrhagia who had no evidence of leiomyoma or endometrial disease at abdominal US and Vabra curettage, respectively. ${ }^{17}$

The endovaginal sonographic criteria Fedele et al used to diagnose adenomyosis included poorly defined heterogeneous area(s) containing 1-3 mm diameter round anechoic lakes within the myometrium.

With these criteria, Fedele et al achieved $80 \%$ sensitivity and $74 \%$ specificity in diagnosing diffuse adenomyosis. Although these results compare favorably with our study results regarding sensitivity $83.3 \%$, yet it differs in specificity as we achieved an $86.8 \%$ specificity, this could be explained by that we used more recent sonographic criteria of adenomyosis like the linear striations and globular configuration of the uterus, in addition that Fedele et al studied a selected group of patients and, therefore, their results cannot be extrapolated to the general population. ${ }^{17}$

Bazot et al found that TV U/S allowed the diagnosis of adenomyosis with high accuracy. According to their study, the sensitivity specificity and PPV and NPV of transvaginal sonography were $65.0 \%, 97.5 \%, 92.8 \%$ and $88.8 \%$, respectively. ${ }^{12}$ 
A meta-analysis on the accuracy of sonography in the diagnosis of adenomyosis showed that it had sensitivity of $82.5 \%(95 \%$ confidence interval, 77.5-87.9) and specificity of $84.6 \%(79.8-89.8)$ with a positive likelihood ratio of $4.7(3.1-7.0)$ and a negative likelihood ratio of 0.26 $(0.18-0.39){ }^{18}$

The 2 false negative cases in this study were misdiagnosed as leiomyoma and that also is not uncommon. The sonographic distinction of adenomyoma from leiomyoma has been described by Fedele et al the presence of a heterogeneous focal nodule with indistinct margins and a cystic space is suggestive of adenomyoma. In this study 1 of the 2 cases had a sub-serosal adenomyoma with welldefined borders so it was misdiagnosed as a leiomyoma, the other case there were many leiomyomas which limited the evaluation of the myometrium. ${ }^{17}$

A number of limitations in diagnosing adenomyosis with endovaginal US must be emphasized. The technique is operator dependent, and the sonographic signs of adenomyosis may be subtle. Therefore, the accuracy of endovaginal US may depend on the sonographer experience to a much greater extent than it does with other pelvic abnormalities. Adenomyosis cannot be reliably diagnosed from hard-copy images but must be diagnosed during the course of the real-time examination. The presence of mural leiomyomas can limit the assessment of the adjacent myometrium, particularly when they are multiple or large.

\section{CONCLUSION}

Adenomyosis can be diagnosed with a considerable accuracy by transvaginal ultrasound. The most common sonographic criteria of adenomyosis are heterogeneous myometrial appearance while the most specific criteria are myometrial cysts, sub-endometrial echogenic linear striations and globular configuration of the uterus. Transvaginal US should be the initial imaging modality in patients suspected of having adenomyosis of the uterus. MR imaging can play a complementary role in women enlarged uteri or where large or multiple fibroids are present.

\section{Funding: No funding sources}

Conflict of interest: None declared

Ethical approval: The study was approved by the Institutional Ethics Committee

\section{REFERENCES}

1. Amant F, Moerman $\mathrm{P}$, Neven $\mathrm{P}$, Timmerman D, Limbergen E, Vergote I. Endometrial cancer. Lancet. 2005;366(9484):491-505.
2. Atri M, Reinhold C, Mehio AR, Chapman WB, Bret PM. Adenomyosis: US features with histologic correlation in an in-vitro study. Radiology. 2000;215(3):783-90.

3. Bajka M. Contraception and bleeding disorders-diagnostic contributions by ultrasound. Praxis. 2005;94(11):417-22.

4. Chiang CM, Hill JA. Localization of T cells, interferongamma and HLA-DR in eutopic and ectopic human endometrium. Gynecol Obstet Invest. 1997;43(4):24550.

5. Curtis KM, Hillis SD, Marchbanks PA, Peterson HB. Disruption of the endometrial-myometrial border during pregnancy as a risk factor for adenomyosis. Am J Obstet Gynecol. 2002;187(3):543-4.

6. Harris WJ, Daniell JF, Baxter JW. Prior cesarean section. A risk factor for adenomyosis?. J Reprod Med. 1985;30(3):173-5.

7. Ueki K, Kumagai K, Yamashita H, Li ZL, Ueki M, Otsuki Y. Expression of apoptosis-related proteins in adenomyotic uteri treated with danazol and $\mathrm{GnRH}$ agonists. Int J Gynecol Pathol. 2004;23(3):248-58.

8. Arnold LL, Ascher SM, Schruefer JJ, Simon JA. The nonsurgical diagnosis of adenomyosis. Obstet Gynecol. 1995;86(3):461-5.

9. Atri M, Reinhold C, Mehio AR, Chapman WB, Bret PM. Adenomyosis: US features with histologic correlation in an in-vitro study. Radiology. 2000;215(3):783-90.

10. Benson RC, Sneeden VD. Adenomyosis: a reappraisal of symptomatology. Am J Obstet Gynecol. 1958;76(5):1044-57.

11. Bohlman ME, Ensor RE, Sanders RC. Sonographic findings in adenomyosis of the uterus. AJR Am J Roentgenol. 1987;148(4):765-6.

12. Bazot M, Darai E, Rouger J, Detchev R, Cortez A, Uzan S. Limitations of transvaginal sonography for the diagnosis of adenomyosis, with histopathological correlation. Ultrasound Obstet Gynecol. 2002;20(6):60511.

13. Chiang CM, Hill JA. Localization of T cells, interferongamma and HLA-DR in eutopic and ectopic human endometrium. Gynecol Obstet Invest. 1997;43(4):24550.

14. Colman HI, Rosentha AH. Carcinoma developing in areas of adenomyosis. Obstet Gynecol. 1959;14:342-8.

15. Devlieger R, Hooghe T, Timmerman D. Uterine adenomyosis in the infertility clinic. Hum Reprod Update. 2003;9(2):139-47.

16. Bromley B, Shipp TD, Benacerraf B. Adenomyosis: sonographic findings and diagnostic accuracy. J Ultrasound Med. 2000;19(8):529-34.

17. Fedele L, Bianchi S, Dorta M, Arcaini L, Zanotti F, Carinelli S. Transvaginal ultrasonography in the diagnosis of diffuse adenomyosis. Fertil Steril. 1992;58(1):94-7.

18. Vora IM, Raizada RM, Rawal MY, Chadda JS. Adenomyosis. J Postgrad Med. 1981;27(1):7-11.

Cite this article as: Hussein NAM, Refaey MHE.

Evaluation of transvaginal ultrasound role in the prediction of adenomyosis: correlation with histopathology. Int J Reprod Contracept Obstet Gynecol 2021;10:2987-92. 